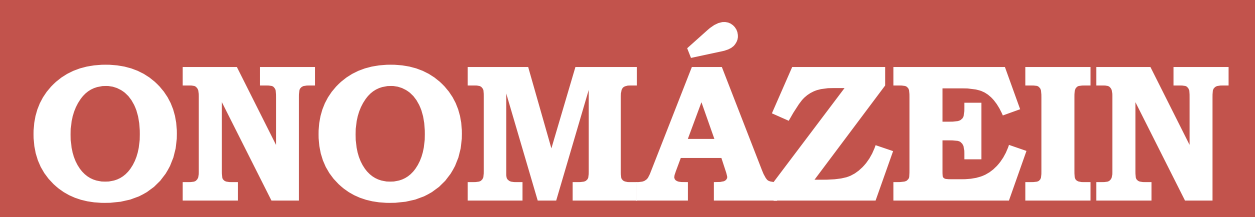

Revista de lingüística, filología y traducción
PONTIFICIA UNIVERSIDAD CATÓLICA DE CHILE FACULTAD DE LETRAS

\title{
Tipos de turismo. Denominaciones \\ y uso actual en España, Argentina, \\ Colombia, México y Perú*
}

Types of tourism. Names and

current use in Spain, Argentina,

Colombia, Mexico and Peru

\section{Pedro Mogorrón Huerta}

Universidad de Alicante

Número especial

- VII -

Discurso

turístico,

lenguas y

traducción

2020
ONOMÁZEIN | Número especial VII - Discurso turístico, lenguas y traducción: 145-174

DOI: 10.7764/onomazein.ne7.10

ISSN: 0718-5758

\section{(c) (1) $\Theta$}

Pedro Mogorrón Huerta: Departamento de Traducción e Interpretación, Universidad de Alicante. ORCID: 0000-0003-2433-063X

Fecha de recepción: octubre de 2019

Fecha de aceptación: marzo de 2020 


\section{Resumen}

En el marco de este artículo, realizamos una investigación que nos permita averiguar si las denominaciones de los tipos de turismo son las mismas en los países que utilizan el español como lengua oficial. Para ello, extraemos en una primera fase (con el programa Sketch Engine) los tipos de turismo que aparecen en las últimas versiones de las guías oficiales de turismo de España, Argentina, Colombia, México y Perú, así como de dos guías de turismo de la Organización Mundial de Turismo. A continuación, en aras de examinar el contenido cuantitativo en tipos de turismo de estas guías oficiales incluimos otros tipos de turismo recopilados en artículos de investigación citados en este artículo. Finalmente, para conocer la vigencia y el uso común de los 98 tipos de turismo que forman parte de este análisis, realizamos, para todos ellos, una búsqueda textual en periódicos referenciales y en páginas webs especializadas en turismo de estos cinco países.

Palabras clave: tipos de turismo; denominaciones; uso común; diatopía; variación.

\section{Abstract}

For this article we carry out an investigation that allows us to find out if the names of the types of tourism are the same in the countries that use Spanish as their official language. For this end, as a first step, we extract - with the Sketch Engine program - the types of tourism that appear in the latest versions of the official tourism guides of Spain, Argentina, Colombia, Mexico and Peru, as well as in two tourism guides of the World Tourism Organization. Then, in order to examine if the content in types of tourism of these official guides is complete or not, we include other types of tourism compiled in research articles referred to in this article. Finally, in order to know the validity and common use or not of the 98 types of tourism that are part of this analysis, for all of them, we carry out a textual search in referential newspapers and on specialized websites about tourism concerning these five countries.

Keywords: types of tourism; names; common use; diatopy; variation.

* Queremos agradecer a Lucía Navarro Brotons y a Analía Cuadrado Rey las observaciones formuladas durante la lectura de este artículo. 


\section{Introducción}

El mundo del turismo o del viajero está conociendo desde mediados del siglo XX un auge continuo e imparable, pasando de ser un fenómeno social y elitista a otro de masas, fruto de los cambios de los métodos de producción y de organización económica y social.

La Organización Mundial del Turismo (OMT), principal organización internacional fundada en 1974, presenta la siguiente definición de turismo: "incluye las actividades que realizan las personas durante sus viajes y estancias en lugares distintos al de su entorno habitual, por un periodo de tiempo consecutivo inferior a un año, con fines de ocio, por negocios y por otros motivos" (OMT, 1991: 12)ㄱ. Actualmente, en la página oficial de la OMT² se encuentra esta definición: "El turismo es un fenómeno social, cultural y económico que supone el desplazamiento de personas a países o lugares fuera de su entorno habitual por motivos personales, profesionales o de negocios. Esas personas se denominan viajeros (que pueden ser o bien turistas o excursionistas; residentes o no residentes) y el turismo abarca sus actividades, algunas de las cuales suponen un gasto turístico".

En el campo de la investigación y de la producción científica, el turismo, de acuerdo a su carácter poliédrico, es actualmente un campo de trabajo transversal y fuente de interés para numerosas disciplinas de entre las que destacamos la lingüística, la sociología, la geografía, la economía, la antropología, la psicología, etc. Los miles y miles de materiales turísticos que se producen en el mundo, tanto en soporte papel (folletos, pósteres, guías turísticas, anuncios, etc.) como, cada vez más, en soporte electrónico (páginas webs, folletos digitales, apps, etc.), atestiguan el auge y la enorme importancia económica de este sector.

En el campo de la investigación del contenido y del uso lingüístico de los textos turísticos, investigación realmente relacionada con el marco de este trabajo, numerosos estudios, en múltiples lenguas', han analizado los diferentes tipos de textos turísticos publicitarios y su contenido. Se trata de investigaciones que han tratado exhaustivamente la lengua y la terminología del turismo, la idiomaticidad de los términos del turismo, la traducción y sus problemáticas, la neología, la variación diatópica, la enseñanza del turismo, etc.

De todos estos estudios se desprende que a primera vista no hay unanimidad en considerar el lenguaje del turismo como lenguaje o lengua de especialidad debido a que la mayoría de

$1 \quad$ Esta definición fue sancionada en la Conferencia sobre Estadísticas de Viajes y Turismos celebrada en Ottawa en 1991. Ver referencia en papel y on-line en la bibliografía. Todos los enlaces citados en este trabajo estaban operativos el 26 de junio de 2020.

2 https://www.unwto.org/es/glosario-terminos-turisticos.

3 Este trabajo se va a centrar en descripciones de denominaciones relacionadas con tipos de turismo en español. Por ello, preferiblemente utilizaremos referencias de trabajos realizados en este idioma. 
sus textos se dirigen al público general, manteniendo el valor terminológico originario en la lengua común. Sin embargo, como señala Calvi (2000: 42-44), el lenguaje del turismo presenta al mismo tiempo una parte más especializada empleada por los trabajadores del sector (agencias de viaje, guías, restaurantes, hoteles, publicidad y comunicación, etc.), que llegan a hacer de él un campo interdisciplinar.

\section{Presencia de los tipos de turismos (TT) en las guías oficiales de turismo}

Es preciso destacar que, ante el incremento exponencial del número de turistas cada vez más y mejor informados, el sector turístico, aunque sigue presentando ofertas clásicas, se renueva constantemente de cara a seguir creciendo con la oferta de productos totalmente innovadores. Esta amplia oferta genera un amplísimo abanico de posibilidades, de productos turísticos o de TT que el turista podrá seleccionar en función de su edad, de sus motivaciones, de sus apetencias de ocio, de cultura, de relajación, de aventura, de conocimientos o de sus recursos económicos, entre otros. Finalmente, creemos conveniente señalar y recordar que, por regla general, es la combinación de la oferta y de la demanda la que origina la existencia del producto turístico.

Este abanico de posibilidades y sus denominaciones o TT es el que nos interesa de cara a la investigación que deseamos realizar en el marco de este artículo. En efecto, deseamos analizar las denominaciones de los TT desde una óptica diatópica, para averiguar si se utilizan los mismos TT en España, Argentina, Colombia, México y Perú ${ }^{6}$.

Es decir, caparecen las mismas denominaciones de turismo en las guías oficiales de turismo (GOT)? ¿Se utilizan los mismos términos en estos 5 países, que tienen una misma lengua oficial, o por el contrario esas tipologías y denominaciones presentan diferencias apreciables?

4 Estas motivaciones están dando lugar a una segmentación del mercado turístico y a la creación de perfiles turísticos (ver Molina Collado y otros, 2007; Beltrán-Bueno y Parra-Meroño, 2017).

5 La selección de estos países se basa en el número de habitantes y en el contacto con profesores universitarios que nos han ayudado a verificar el uso y las denominaciones de los tipos de turismo.

6 Es indiscutible que la riqueza léxica del español debido a sus más de 500 millones de hablantes, su uso como lengua cooficial en 20 países genera variantes o variedades diacrónicas, diatópicas y diafásicas. De la misma forma que en determinadas zonas geográficas se usan unos términos en detrimento de otros, por ejemplo: computadora/ordenador, piso/departamento, billete/boleto, carro/auto, melocotón/durazno, etc., queremos ver la denominación que se utiliza en estos cinco países a la hora de referirse a numerosos tipos de turismo. Este tipo de estudio, de cara a conocer las diferentes posibilidades existentes en países con una misma lengua oficial, es no solamente muy útil, sino que debería ser de obligado cumplimiento en aras de evitar un uso eurocéntrico o geolingüístico de la terminología del español y de reivindicar un uso pluricéntrico. 


\subsection{Tipos de turismo (TT) en guías oficiales de turismo}

En una primera fase, analizaremos y compararemos los TT contenidos en las guías oficiales de cada uno de los países mencionados7, así como su denominación. A saber:

- en España, el Plan Nacional e Integral de Turismo (2015); el Plan del Turismo Español Horizonte $2020^{8}$;

- en Argentina, el Plan Federal Estratégico de Turismo Sustentable 2025;

- en Colombia, el Plan Sectorial de Turismo (2018-22);

- en México, el Programa Sectorial de Turismo (2012-2018);

— en Perú, el Plan Estratégico Nacional de Turismo, PENTUR (2012-2021).

Para ello, se analizarán las GOT con la herramienta de análisis textual Sketch Engine (ver captura de pantalla 1), que se completará con una lectura manual para confirmar todos los datos presentados en este estudio. Después de realizar la búsqueda mixta informática y manual ${ }^{9}$ y de extraer las ocurrencias encontradas, citaremos a modo de ejemplo la frecuencia de aparición del término turismo y, a continuación, indicaremos por orden alfabético los diferentes tipos de turismo encontrados para cada guía y país ${ }^{10}$.

\section{España}

\section{Plan Nacional e Integral de Turismo $2015^{11}$ (1)}

7 Para cada una de estas guías oficiales, proporcionamos en la bibliografía un enlace informático de acceso o link operativo, término utilizado preferencialmente en Argentina, Colombia, México y Perú.

8 Se han analizado dos guías oficiales españolas de cara a observar la coincidencia en el contenido de tipos de turismo en diferentes versiones.

9 El uso de Sketch Engine sirve para detallar rápidamente el número de veces que aparece un término o una determinada secuencia léxica, como turismo. Es imposible hacer esta recopilación manualmente por el enorme número repetitivo de uso de determinadas palabras o conceptos que va de 216 veces a un máximo de 992 en las GOT.

10 Cuando en una determinada GOT aparezca una denominación que incluya varios tipos de turismo (incluso aunque pensemos que son tipos totalmente diferentes), la contabilizaremos como un único tipo de turismo para respetar la terminología tomada en esa guía. Ej.: en el Plan de Turismo Español 2020 encontramos T. cultural y de ciudad. También se analizarán las diferentes denominaciones utilizadas para referirse a un determinado tipo o tipos de turismo que pueden dar pie a desajustes de equivalencias en diferentes países. Así, en el Plan Nacional e Integral de Turismo $(2015,1)$, encontramos T. de reuniones, congresos e incentivos o MICE (meetings, incentives, conferences, exhibitions), y en la GOT de Colombia, T. de reuniones, convenciones, eventos corporativos y sociales (lunas de miel, matrimonios, etc.).

11 Para cada tipo de turismo indicaremos turismo con una T mayúscula seguido de un punto y a continuación indicaremos esa tipología. En estos dos listados de los tipos de turismo que aparecen en las guías oficiales de turismo español, se puede apreciar que solamente coinciden 7 tipos de turismo que se han destacado en negrita. 
El término turismo aparece 216 veces. Se han extraído 22 tipologías de turismo: ecoturismo, T. de ciudad o de City-break, T. de comercio, T. cultural, T. de cruceros, T. de golf, T. de interior, T. de naturaleza, T. de naturaleza y biodiversidad, T. de reuniones, congresos e incentivos o MICE (meetings, incentives, conferences, exhibitions), T. de sol y playa, T. emisor, T. enogastronómico, T. internacional, T. nacional, $\mathbf{T}$. náutico, T. no residente, T. ornitológico, T. sostenible o medioambiental, T. urbano.

\section{Plan del Turismo Español Horizonte $2020^{12}$}

Se han recopilado 599 ocurrencias, de las que se han extraído y seleccionado 21 tipologías de turismo: T. accesible para todos, T. cultural y de ciudad, T. de masas, T. de ocio y vacaciones, T. de sol y playa, T. de salud y bienestar, T. de reuniones, congresos e incentivos, T. deportivo (T. de golf, T. náutico, T. de esquí y de montaña), T. emisor, T. internacional, T. nacional, T. residencial, T. rural y de interior, T. rural y activo, T. urbano, T. vacacional (ver captura de pantalla 1 ).

\section{CAPTURA DE PANTALLA 1}

Resultados Plan de Turismo 2020
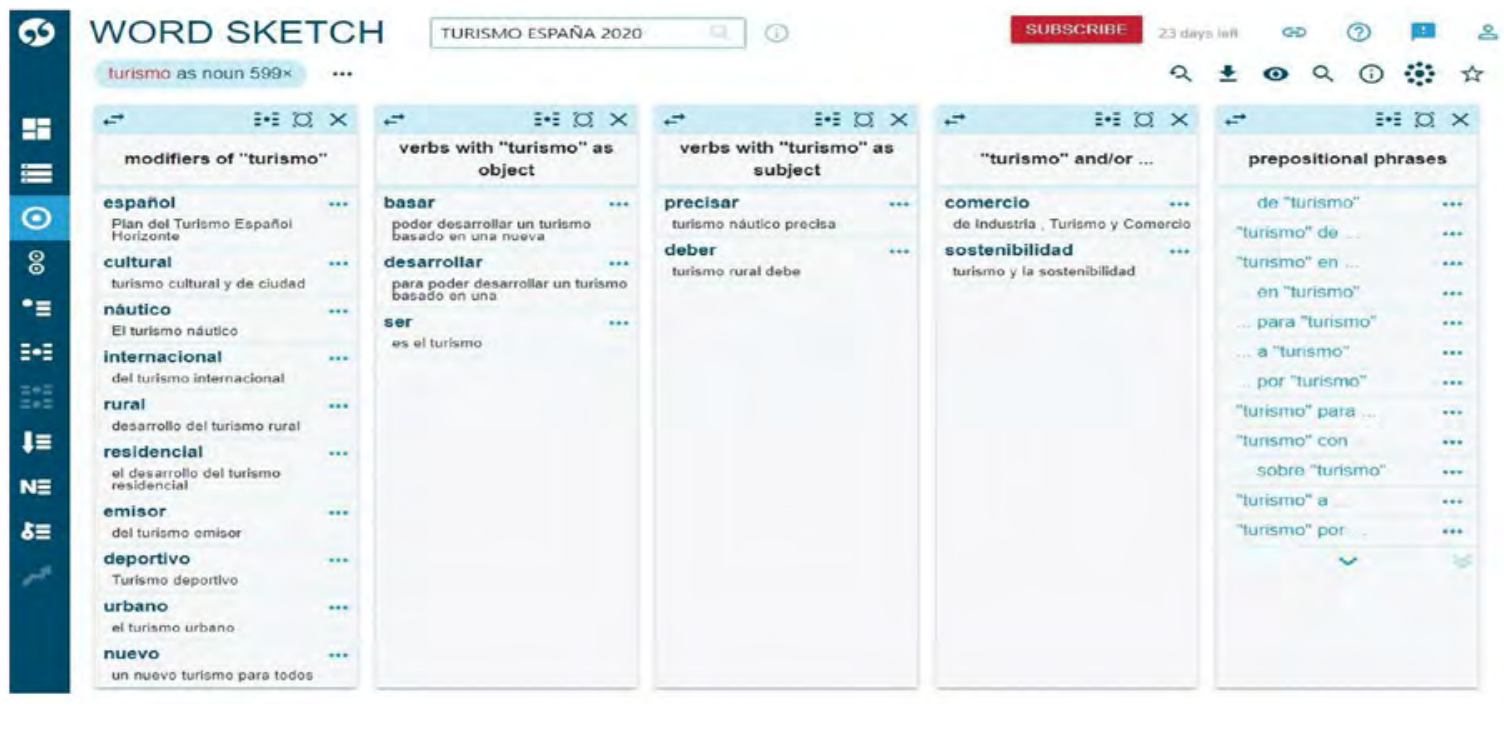

12 Observamos que la denominación de las tipologías turísticas presente en las dos versiones de las guías españolas no coincide en los siguientes casos: T. cultural / T. cultural y de ciudad; T. de ciudad o de City-break / T. cultural y de ciudad; T. de reuniones, congresos e incentivos o MICE (meetings, incentives, conferences, exhibitions) / T. de reuniones, congresos e incentivos; T. de interior / T. rural $y$ de interior. 


\section{Argentina \\ Plan Federal Estratégico de Turismo Sustentable 2025}

El término turismo aparece 992 veces, de los que se han extraído estas 22 tipologías de turismo: cicloturismo, ecoturismo, T. de bienestar, Observación de aves y senderismo de largo recorrido, T. de la fe, T. educativo/idiomático, T. emisivo, T. estudiantil, T. gastronómico, T. gastronómico y del vino, T. internacional, T. interno, T. médico, T. náutico, T. náutico, cruceros de ultramar, fluviales y lacustres, T. social, T. receptivo, T. responsable, T. rural comunitario, T. sustentable ${ }^{13}$.

\section{Colombia \\ Plan Sectorial de Turismo (2018-22)}

La palabra turismo aparece 506 veces y encontramos las referencias a estos 29 tipos de turismo ${ }^{14}$ : agroturismo, ecoturismo, T. amarillo, T. azul, T. científico, T. cultural, T. de aventura, T. de cultura, T. de gastronomía, T. de inversión, negocios y emprendimiento, T. de música y religión, T. de naturaleza, T. de negocios, T. de patrimonio, T. de playa y cruceros, T. de reuniones, convenciones, eventos corporativos y sociales (lunas de miel, matrimonios, etc.), T. de salud y bienestar, T. de sol, T. incluyente (personas mayores, jóvenes, comunidades, equidad de género, accesibilidad y turismo social), T. interior, T. morado, T. musical, T. naranja, T. náutico, T. rojo, T. sostenible, T. social, T. urbano y metropolitano, T. verde.

13 Esta guía incluye la siguiente definición (p. 52) de desarrollo sustentable: "El turismo se desarrolla en armonía con los recursos naturales y culturales a fin de garantizar sus beneficios a las futuras generaciones. El desarrollo sustentable se aplica en tres ejes básicos: ambiente, sociedad y economía”. La enunciación de este principio y su alcance tiene asiento en el artículo 41 de la Constitución Nacional, que establece el derecho a un medio ambiente sano. Un desarrollo turístico sustentable debe tomar en cuenta, en forma simultánea, no alternativa, todos los elementos del ambiente, tal como lo reflejan los diversos parágrafos contenidos en la Carta Mundial de Turismo Sostenible (Lanzarote, España, 1995). Se trata de un ejemplo muy ilustrador de las diferentes denominaciones que puede recibir un mismo tipo de turismo en diferentes países que tengan el español como lengua oficial.

14 Podemos observar que el plan sectorial de turismo colombiano utiliza otro tipo de clasificación tipológica incluyendo los tipos de turismo en 6 líneas estratégicas a partir de los colores del arcoíris que no son sino clasificaciones temáticas de la actividad turística. Por ello, resulta interesante el siguiente párrafo encontrado en la pág. 6 del plan sectorial: "El fortalecimiento de la oferta turística desarrollará los productos del Arcoíris Turístico de la propuesta programática del Plan de Gobierno, así: (1) verde: naturaleza, ecoturismo, agroturismo, aventura y científico; (2) amarillo: sol, playa y cruceros; (2) naranja: cultura, gastronomía, patrimonio, música y religión; (4) azul: salud y bienestar; (5) morado: inversión, negocios y emprendimiento; (6) rojo: turismo de reuniones, convenciones, eventos corporativos y sociales (lunas de miel, matrimonios, etc.); y, (7) gris: turismo incluyente (personas mayores, jóvenes, comunidades, equidad de género, accesibilidad y turismo social)". 


\section{México}

\section{Plan Sectorial de Turismo (2012-18)}

La palabra turismo aparece 195 veces y se han extraído las siguientes 17 tipologías de turismo: ecoturismo y aventura, geoturismo, T. cultural, T. de lujo y reuniones, T. de naturaleza, T. de negocios, T. de nicho (como deportes, cultura, gastronomía, ecológico), T. de salud, T. de sol y playa, T. deportivo y de lujo, T. doméstico, T. internacional, T. nacional, T. religioso, T. rural, T. sustentable, T. vivencial.

\section{Perú}

\section{Plan Estratégico Nacional de Turismo (2012-2021)}

En Perú, en el Plan Estratégico Nacional de Turismo (2012-2021), la palabra turismo aparece 218 veces, pero solamente encontramos 11 tipos de turismos: T. cultural, T. de aventuras, T. de masas, T. de naturaleza, T. de negocios, T. global, T. interno, T. multitemático, T. sostenible, T. receptivo, T. rural.

¿Corresponden los tipos de turismo que aparecen en los diferentes planes? ¿Y la denominación terminológica? Reproducimos en una tabla los diferentes tipos de turismos extraídos de las GOT de los 5 países ${ }^{15}$ (ver tabla 1).

\section{TABLA 1}

Contenido de tipos de turismo en las guías

\begin{tabular}{|c|c|c|c|c|c|}
\hline TIPO DE TURISMO & ESPAÑA & ARGENTINA & COLOMBIA & MÉXICO & PERÚ \\
\hline agroturismo & - & - & + & - & - \\
\hline cicloturismo & + & + & - & - & - \\
\hline ecoturismo & + & + & + & $\begin{array}{l}\text { + Ecoturismo } \\
\text { y aventura }\end{array}$ & - \\
\hline geoturismo & - & - & - & + & - \\
\hline $\begin{array}{l}\text { Observación de } \\
\text { aves y senderismo } \\
\text { de largo recorrido }\end{array}$ & - & + & & & \\
\hline
\end{tabular}

15 En la tabla 1, una "+" indica que el tipo de turismo aparece con identidad total, el signo "-" indica que no aparece y, cuando aparece con una denominación con alguna variación, se ha transcrito en la columna del país correspondiente la forma que aparece en su guía, pero por debajo de la línea equivalente (ver, por ejemplo, T. cultural y T. cultural y de ciudad). Finalmente, cabe señalar que cuando aparece una identidad parcial se ha subrayado la denominación en negrita. Véanse, por ejemplo, las denominaciones de T. cultural. 


\begin{tabular}{|c|c|c|c|c|c|}
\hline T. accesible para todos & + & - & - & - & - \\
\hline T. amarillo & - & - & + & - & - \\
\hline T. azul & - & - & + & - & - \\
\hline T. científico & - & - & + & - & - \\
\hline $\begin{array}{l}\text { T. cultural } \\
\text { T. de patrimonio }\end{array}$ & $\begin{array}{l}+ \\
\text { T. cultural y } \\
\text { de ciudad }\end{array}$ & - & $\begin{array}{l}+ \\
+\mathrm{T} \text {. de cultura } \\
+\mathrm{T} \text {. de } \\
\text { patrimonio }\end{array}$ & + & + \\
\hline T. de aventura & - & - & + & - & + \\
\hline T. de bienestar & - & + & & & \\
\hline $\begin{array}{l}\text { T. de ciudad o } \\
\text { T. urbano }\end{array}$ & $\begin{array}{l}+ \\
\text { T. de ciudad } \\
\text { o City-break } \\
+\end{array}$ & - & $\begin{array}{l}- \\
- \\
+ \text { T. urbano y } \\
\text { metropolitano }\end{array}$ & - & - \\
\hline T. de comercio & + & - & - & - & - \\
\hline T. de cruceros & + & - & - & - & - \\
\hline T. de esquí y montaña & + & - & - & - & - \\
\hline T. de golf & + & - & - & - & - \\
\hline T. de interior & + & - & - & - & - \\
\hline T. de lujo y reuniones & - & - & - & + & - \\
\hline T. de masas & + & - & - & & + \\
\hline T. de naturaleza & + & - & + & + & + \\
\hline $\begin{array}{l}\text { T. de naturaleza y } \\
\text { biodiversidad }\end{array}$ & + & - & - & - & - \\
\hline T. de negocios & - & - & $\begin{array}{l}+\mathrm{T} \text {. de negocios } \\
+\mathrm{T} \text {. de inver- } \\
\text { sión, negocios } \\
\text { y emprendi- } \\
\text { miento } \\
\text { T. de negocios }\end{array}$ & + & + \\
\hline T. de nicho & - & - & - & + & - \\
\hline T. de ocio y vacaciones & + & - & - & - & - \\
\hline $\begin{array}{l}\text { T. de reuniones } \\
\text { congresos e } \\
\text { incentivos }\end{array}$ & $\begin{array}{l}+ \\
\text { T. de reunio- } \\
\text { nes, congre- } \\
\text { sos e incen- } \\
\text { tivos o MICE } \\
\text { (Meetings, } \\
\text { incentives, } \\
\text { conferences, } \\
\text { exhibitions) }\end{array}$ & & $\begin{array}{l}\text { + T. de reunio- } \\
\text { nes, convencio- } \\
\text { nes, eventos } \\
\text { corporativos } \\
\text { y sociales (lu- } \\
\text { nas de miel, } \\
\text { matrimonios). }\end{array}$ & & \\
\hline
\end{tabular}




\begin{tabular}{|c|c|c|c|c|c|}
\hline $\begin{array}{l}\text { T. de salud } \\
\text { T. de salud y } \\
\text { bienestar }\end{array}$ & - & $\begin{array}{l}- \\
+ \text { T. médico } \\
+ \text { T. de } \\
\text { bienestar }\end{array}$ & $\begin{array}{l}+ \\
+\end{array}$ & + & - \\
\hline $\begin{array}{l}\text { T. de sol } \\
\text { T. de sol y playa } \\
\text { T. de playa y cruceros }\end{array}$ & - & - & $\begin{array}{l}+ \\
- \\
+ \text { T. de playa } \\
\text { y cruceros } \\
\text { T. de sol }\end{array}$ & - & - \\
\hline T. deportivo & + & - & - & $\begin{array}{l}+ \\
\text { y de lujo }\end{array}$ & - \\
\hline $\begin{array}{l}\text { T. educativo / } \\
\text { idiomático }\end{array}$ & - & + & - & - & - \\
\hline T. emisor & + & + T. emisivo & - & - & - \\
\hline T. gastronómico & $\begin{array}{l}+ \\
\text { T. enogas- } \\
\text { tronómico }\end{array}$ & $\begin{array}{l}+ \\
+ \text { T. gastro- } \\
\text { nómico y } \\
\text { del vino }\end{array}$ & $\begin{array}{l}+\mathrm{T} \text {. de gas- } \\
\text { tronomía }\end{array}$ & - & - \\
\hline T. estudiantil & - & + & - & - & - \\
\hline T. global & - & - & - & - & + \\
\hline T. incluyente & - & - & + & - & - \\
\hline T. internacional & + & + & - & + & - \\
\hline $\begin{array}{l}\text { T. interior } \\
\text { T. doméstico }\end{array}$ & - & - & + & $\begin{array}{l}- \\
+\mathrm{T} \\
\text { doméstico }\end{array}$ & - \\
\hline T. interno & - & + & & & \\
\hline T. morado & - & - & + & - & - \\
\hline T. multitemático & - & - & & - & + \\
\hline T. musical & - & - & + & & - \\
\hline $\begin{array}{l}\text { T. nacional } \\
\text { T. interno } \\
\text { T. doméstico }\end{array}$ & + & - & - & $\begin{array}{l}+ \\
- \\
+\mathrm{T} . \\
\text { doméstico }\end{array}$ & $\begin{array}{l}- \\
+\end{array}$ \\
\hline T. naranja & - & - & $x$ & - & - \\
\hline T. náutico & + & $\begin{array}{l}+ \\
\text { + T. náutico, } \\
\text { cruceros de } \\
\text { ultramar, } \\
\text { fluviales y } \\
\text { lacustres }\end{array}$ & $\begin{array}{l}+ \\
\text { T. de playa } \\
\text { y cruceros }\end{array}$ & - & - \\
\hline
\end{tabular}




\begin{tabular}{|c|c|c|c|c|c|}
\hline T. no residente & + & - & - & - & - \\
\hline T. ornitológico & + & $\begin{array}{l}\text { - } \\
\text { Observación } \\
\text { de aves y } \\
\text { senderismo } \\
\text { de largo } \\
\text { recorrido }\end{array}$ & - & - & - \\
\hline T. receptivo & - & + & - & - & + \\
\hline $\begin{array}{l}\text { T. religioso } \\
\text { o T. de la fe }\end{array}$ & - & $\begin{array}{l}- \\
+\end{array}$ & $\begin{array}{l}- \\
+ \text { T. de música } \\
\text { y religión }\end{array}$ & + & - \\
\hline T. residencial & + & - & - & - & - \\
\hline T. responsable & & + & - & - & - \\
\hline T. rojo & - & - & + & - & - \\
\hline T. rural & $\begin{array}{l}+ \\
\text { T. rural y de } \\
\text { interior } \\
\text { T. rural y } \\
\text { activo }\end{array}$ & $\begin{array}{l}- \\
+ \text { T. rural } \\
\text { comunitario }\end{array}$ & - & + & + \\
\hline T. social & - & + & + & - & - \\
\hline $\begin{array}{l}\text { T. sostenible o } \\
\text { medioambiental } \\
\text { T. sustentable }\end{array}$ & + & $\begin{array}{l}- \\
+\end{array}$ & $\begin{array}{l}+ \\
-\end{array}$ & $\begin{array}{l}- \\
+\end{array}$ & + \\
\hline T. vacacional & + & - & - & - & - \\
\hline T. verde & - & - & + & - & - \\
\hline T. vivencial & - & - & - & + & - \\
\hline TOTAL: 52 & $\begin{aligned} \mathbf{1} & =\mathbf{2 2} \\
\mathbf{2} & =\mathbf{2 1} \\
\mathbf{1 + 2} & =\mathbf{3 0}^{16}\end{aligned}$ & 22 & 29 & 17 & 11 \\
\hline
\end{tabular}

Si sumamos los diferentes tipos de turismo, las 6 guías incorporan 52 tipos de turismo tal y como aparece en la tabla 1. Por países, 30 tipos de turismo en España, 22 en Argentina, 29 en Colombia, 17 en México y 11 en Perú. Cada país incluye en su guía oficial determinados tipos de turismo que no coinciden obligatoriamente ni en la tipología ni en la denominación.

El análisis exhaustivo de las guías oficiales de turismo argentino, colombiano, español, mexicano y peruano que tienen como lengua oficial el español nos permite realizar las siguientes observaciones.

16 La suma de los TT de las 2 guías españolas da 30 tipos de turismo diferente. 
Las coincidencias encontradas en las tipologías de los tipos de turismo (TT) son las siguientes:

— Solamente un tipo de turismo aparece en las 6 GOT analizadas. Se trata de T. sostenible o sustentable ${ }^{17}$.

- Solamente dos tipos de turismo aparecen en las guías de 4 países simultáneamente: T. de naturaleza, ecoturismo.

- 8 tipos de turismo aparecen en las guías de 2 países simultáneamente: T. cultural, T. gastronómico o de gastronomía, T. internacional, T. religioso, de la fe o T. de música y religión, T. de negocios, T. de salud, T. nacional o interno, T. náutico.

- 3 tipos de turismo aparecen en las guías de 2 países simultáneamente. Se trata de T. de masas, T. de reuniones, congresos e incentivos, T. social.

En relación con las denominaciones de los tipos de turismo presentes en las GOT de los 5 países, se aprecian varios casos.

- Una única e idéntica denominación en las GOT que lo incluyen para un tipo de turismo. Por ej.: ecoturismo y $\mathrm{T}$. de naturaleza.

- Varias denominaciones para un mismo tipo de turismo ${ }^{18}$. Es el caso, por ejemplo, de T. de ciudad o T. urbano, que también recibe en México la denominación de T. urbano y metropolitano e incluso aparece en la guía española (2020) como T. cultural y de ciudad. Otras posibilidades encontradas son: T. cultural en España frente a T. cultural y de ciudad en España y T. de cultura o de patrimonio en México; T. religioso en España y en México frente a T. de la fe en Argentina o T. de música y religión en Colombia; T. sostenible en España, Colombia y Perú frente a T. sustentable en Argentina y en México.

\subsection{Tipos de turismo en las guías de la OMT}

A efectos de poder valorar las coincidencias, así como el contenido en tipos de turismo (TT) de las guías ya señaladas con otras GOT, analizaremos las versiones en español de dos documentos de la OMT. A saber: Collection of Domestic Tourism Statistics, 2004, y el documento UNWTO Tourism definition.

En la versión española de Collection of Domestic Tourism Statistics (CDTS), la OMT presenta, en función de la actividad desarrollada, los 20 tipos de turismo que reproducimos a continua-

17 Mientras en España se usa la denominación turismo sostenible, en las GOT de Argentina y México figura T. sustentable, y en Colombia y en Perú, turismo sostenible.

18 Cuando la denominación de un determinado tipo de turismo es parcial o totalmente diferente, la hemos incluido en el cuadro resumen 1, disponible en el anexo 1. Es el caso, por ejemplo, de turismo de ciudad o turismo urbano, que aparecen en las guías españolas como T. de ciudad, T. de ciudad o City-break; T. urbano o, incluso, T. cultural y de ciudad. En México, en cambio, figura como T. urbano y metropolitano. 
ción, y que denomina productos turísticos: T. de sol y playa (2), T. de nieve, $\underline{T}$. de aventura (2), T. rural (4), T. cultural (2), T. de formación, T. gastronómico (3), T. de negocios (2), T. alternativo,

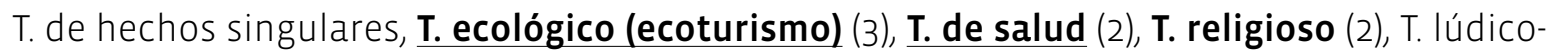
festivo, T. residencial (1), T. de compras, T. de excursiones, T. de parques temáticos.

En el documento UNWTO Tourism definition de la OMT (UTD), se incluyen en tres idiomas los siguientes 17 tipos de turismo ${ }^{19}$ : ecoturismo (4), enoturismo, T. costero, marítimo y de aguas interiores (costero se refiere a actividades turísticas que tienen su base en tierra costera, como la natación, el surf, tomar el sol y otras actividades costeras de ocio, recreo y deporte

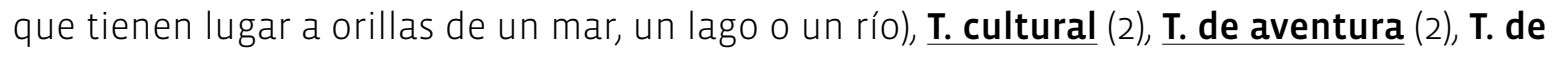
bienestar (1), T. de montaña, T. de negocios (2) (relacionado con la industria de reuniones), $\mathbf{T}$. de salud (2) (engloba al T. de bienestar y al T. médico), T. deportivo (2), T. educativo (1), $\underline{\text { T. gas- }}$ tronómico o de gastronomía (3) (enoturismo ${ }^{20}$ es un subtipo del T. gastronómico), T. médico (1), T. rural (4), T. urbano o de ciudad (2).

En ambos casos, hemos destacado:

- en negrita los productos turísticos que aparecen, a la par, en los dos documentos de la OMT y en alguna de las GOT analizadas, indicando asimismo en cada caso, entre paréntesis, el número de coincidencias totales encontradas en las otras 5 guías;

- con subrayado los productos turísticos que aparecen simultáneamente en los dos documentos de la OMT.

También se puede observar que en el contenido de los textos de la OMT aparecen nuevos tipos de turismo que no figuran en las otras 6 guías oficiales. A saber:

- en COTS, 8 nuevos tipos: enoturismo, T. de nieve, T. de formación, T. alternativo, T. de hechos singulares, T. Iúdico-festivo, T. de excursiones, T. de parques temáticos;

- en el Unwto Tourism definition, 3 nuevos tipos: enoturismo, T. costero, marítimo y de aguas interiores, T. de montaña.

Todas estas observaciones unidas a la lectura del cuadro resumen 1 nos permiten inferir:

- que el contenido en tipos de turismo en los 8 documentos analizados es bastante deficitario;

19 Las principales diferencias consisten en que este documento incluye toda la información en tres idiomas (inglés, francés y español) y en que presenta los tipos de turismo en una pequeña clasificación relacionada con temáticas más específicas.

20 En la versión francesa precisan que el enoturismo es también el turismo del vino (Tourisme du vin); ni en la versión inglesa ni en la española lo indican. 
- que resulta sorprendente ver las escasas coincidencias que se producen no solamente entre las guías oficiales de países diferentes, como ya hemos señalado, sino también y sobre todo entre documentos de un mismo organismo oficial (caso de la OMT), o incluso de un mismo país (caso de las dos guías españolas).

Si comparamos el contenido en TT de las 8 guías, observamos que es realmente escaso en cada caso individual. La suma de las 8 nuevas acepciones incluidas en el CDTS y de las 2 incluidas en el UTD con el número de tipos de turismo presentes en el cuadro 1 reúne un total de 62 productos turísticos. Los datos globales permiten elaborar la siguiente comparativa contrastando el contenido individual frente al contenido global y mostrando muy claramente el escaso contenido individual de cada documento oficial de turismo analizado (ver tabla 2 y gráfico 1 ).

\section{TABLA 2}

Comparativa contenido tipologías por país y guías

\begin{tabular}{lllllllll} 
TIPO TUR & ESP 2015 & ESP2020 & ARGENT & COL & MÉX & PERÚ & CDTS & UTD \\
TOTAL: 62 & $22=35 \%$ & $21=34 \%$ & $22=35 \%$ & $29=47 \%$ & $17=27 \%$ & $11=18 \%$ & $20=31 \%$ & $17=27 \%$ \\
\hline
\end{tabular}

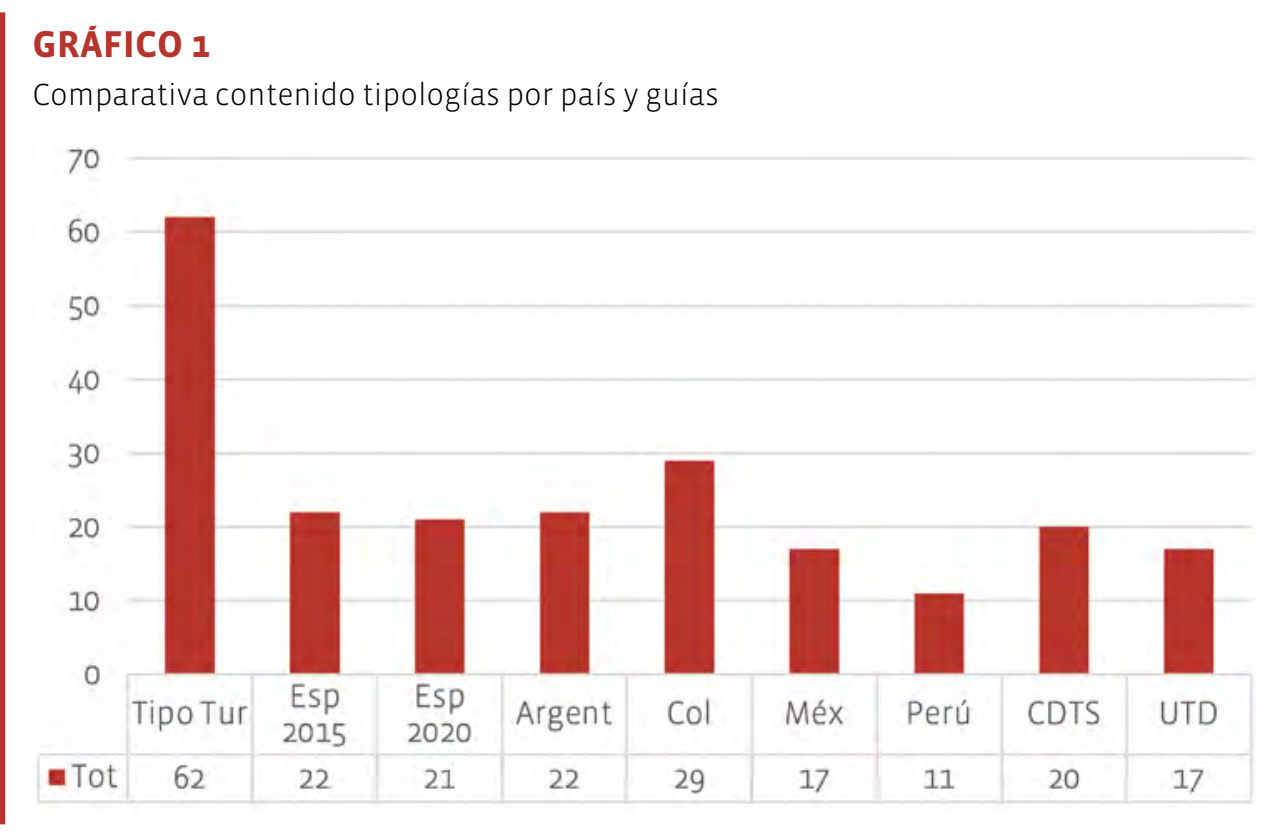

\section{Tipos o productos de turismo existentes}

Hasta este punto, se ha analizado el contenido en TT presentes en las guías oficiales. Ahora queremos, en una segunda fase, investigar si el contenido del cuadro 1 es realmente representativo de la diversidad de productos turísticos existentes en el sector del turismo de hoy en 
día y, además, verificar si se usan las mismas denominaciones en España y en diferentes países hispanoamericanos. Porque existir, efectivamente existen muchos más tipos de turismo², y conviene mencionar que, por regla general, es la combinación de la oferta y de la demanda la que origina la existencia del producto turístico.

Para ello, ampliaremos la tipología de los tipos de turismo, y analizaremos su posible uso en los cinco países ya indicados en la primera parte del estudio. De cara a garantizar la existencia, vigencia e institucionalización, y debido a la gran cantidad de tipos de turismo existentes, trataremos únicamente aquellos tipos que aparecen en las siguientes guías e investigaciones turísticas:

- en guías oficiales de carácter más local; por ejemplo, el libro blanco para una nueva estrategia turística de la comunidad valenciana, que plantea una propuesta de 20 productos turísticos, de los cuales 7 son nuevos: 7. T. de eventos, 9. LGBT travellers, 15. T. de camping (caravaning), 16. T. activo y de naturaleza, 17. T. industrial, 18. T. single, 20. T. cinematográfico. — en los siguientes artículos que resultan pertinentes para esta investigación:

- en Urreta Okeranza (2019), 12 nuevos tipos: T. ferroviario, T. negro, necroturismo, T. literario, T. cinegético, T. termal, T. del bisturí, T. bélico, Micoturismo, T. de pesca, T. sexual, T. solidario, T. ornitológico;

- en Calvi y Mappelli (2011) encontramos: T. termal, T. musical, T. de experiencia;

- en Felipe de Souza (2008), 14 nuevos tipos: T. exterior, T. juvenil, T. familiar, T. de la tercera edad, T. terrestre, T. aéreo, T. marítimo, T. de asentamiento, T. itinerante, T. de golondrina, T. folclórico, T. individual, T. de grupo, T. de paseo;

- en González Pastor y Candel Mora (2018) encontramos otros 7 nuevos tipos de turismo: astroturismo, oleoturismo, T. de vivienda vacacional, T. city break, T. de borrachera, T. solidario o de voluntariado.

En esta segunda fase, para potenciar el interés del estudio y poder conocer y resaltar su uso cotidiano se comprobará la presencia de todos estos TT en diferentes medios de comunicación y de información. Este análisis permitirá observar:

21 Se han elaborado muchas clasificaciones de los diferentes tipos de turismo en función de motivaciones e intereses diferentes. Según el origen del turista, según los precios y el consumo, en función del espacio, del deseo de descanso o de actividad, del aprendizaje, por su forma de viajar, etc. Deseamos destacar también el carácter transversal de la terminología del campo del turismo, como ya señalaron Alcaraz Varó y otros (2000), con términos que pertenecen por lo general a los campos semánticos relacionados con el turismo el alojamiento, el arte, la cultura, el clima, los deportes, el derecho, los espectáculos, la gestión, los juegos, el marketing, el paisaje, la restauración/ gastronomía, los seguros y el viaje. 
- si se utilizan las mismas denominaciones de TT en el sector del turismo en 5 países que tienen el español como lengua oficial (o al menos se intentará conocer la designación utilizada); - si, por el contrario, esas tipologías y denominaciones presentan diferencias apreciables.

No se puede obviar que la irrupción y consolidación de las nuevas tecnologías está teniendo un efecto dominó imparable en el mundo actual. En el campo del turismo, los usuarios navegan cada vez más frecuentemente por internet para organizar sus vacaciones. Por ello, resulta indispensable analizar las denominaciones de los productos turísticos en los países que tengan una misma lengua oficial de cara a conocer la posible similitud/divergencia y facilitar no solamente la comunicación a los expertos turísticos sino también la elección y la organización de sus viajes a los turistas viajeros. Estas últimas comprobaciones serán, pues, de suma importancia para permitirle a los posibles turistas/viajeros conocer las denominaciones de los TT que deben utilizar22.

Hasta la fecha hemos trabajado con GOT y con listados elaborados por especialistas en la materia. Ahora queremos conocer la presencia de estos TT en distintos medios de comunicación que sean representativos de cada país, así como objeto y fuente de consulta referencial. Para ello, una vez elaborada la tabla 3, con las denominaciones de todos los TT recopilados, verificaremos en la prensa ${ }^{23}$ y en internet su uso en cada caso y en los países ya analizados.

22 Posiblemente de entre las numerosas investigaciones del sector del turismo nombradas en la introducción, aquella que menos interés ha despertado hasta la fecha es la relacionada con la comparación y la variación diatópica de la terminología del turismo no solamente entre España y los diferentes países que utilizan el español como lengua oficial, sino también entre los diferentes países hispanoamericanos (ver Sanmartín, 2012, 2016; Suau, 2015). Este fenómeno, por otra parte, es idéntico al observado en otros sectores, por ejemplo, el de la fraseología, donde por fin se empieza a observar un interés cada vez más creciente por recopilar, clasificar y comparar las diferentes unidades y sistemas fraseológicos de cada país.

23 Se analizará en cada país el uso de las denominaciones presentes en el cuadro 3 en un periódico de tirada nacional y, si no apareciese, en internet en páginas webs relacionadas con el turismo (oficiales primero y no oficiales en una segunda fase). Según Tripadvisor (2016) https://www.tripadvisor.com/TripAdvisorln-sights/n2670/6-key-travel-trends-2016, casi un 90\% de los turistas realizan consultas en internet antes de reservar o de contratar un viaje. Para cada país se citan a continuación las páginas webs oficiales, pero no las no oficiales debido a su enorme cantidad. Cuando se encuentre en el periódico se anotará en el cuadro correspondiente el resultado con un "+" seguido de un 1; cuando aparezca en una página web, se indicará con un "+" seguido de un 2, y cuando no aparezca ni en la prensa ni en las páginas de turismo se indicará con un "-”. Estos son los medios referenciales consultados:

- España: el diario El País, el portal oficial de turismo de España (https://www.spain.info/es/), el Diario del viajero (https://www.diariodelviajero.com/), etc.

- Argentina: el diario Clarín, el portal oficial (https://www.argentina.tur.ar), el portal voy de viaje (www.voydeviaje.com.ar), etc.

- Colombia: el diario El Tiempo, el portal oficial Colombia travel (https://colombia.travel/), el por- 
La combinación de estos dos medios de difusión y de consulta que contienen sin lugar a dudas la mayor cantidad de información digitalizada del sector turístico genera una enorme riqueza textual, que posibilita extraer información de manera fiable y recurrente. Al utilizar estos dos medios de comunicación combinados, estamos mostrando la interacción y las producciones terminológicas que se producen en el entorno comunicativo entre los expertos del sector turístico especializado y también entre los futuros turistas/viajeros deseosos de recabar información y de solicitar servicios.

\section{TABLA 3}

Uso de los TT en los 5 países

\begin{tabular}{|c|c|c|c|c|c|c|}
\hline TIP & $\begin{array}{l}\text { TIPO DE TURIS- } \\
\text { MO ENCONTRA- } \\
\text { DO EN GUÍAS } \\
\text { OFICIALES Y } \\
\text { ARTICULOS DE } \\
\text { INVESTIGACIÓN }\end{array}$ & ESPAÑA & ARGENTINA & COLOMBIA & MÉXICO & PERÚ \\
\hline 1 & astroturismo & $\begin{array}{l}+1 \\
\text { T. astro- } \\
\text { nómico }\end{array}$ & $\begin{array}{l}+1 \\
\text { T. astro- } \\
\text { nómico }\end{array}$ & $\begin{array}{l}+2 \\
\text { T. astro- } \\
\text { nómico }\end{array}$ & $\begin{array}{l}+1 \\
\text { T. astro- } \\
\text { nómico }\end{array}$ & $\begin{array}{l}+1 \\
\text { T. astro- } \\
\text { nómico }\end{array}$ \\
\hline 2 & caravaning & +1 & $\begin{array}{l}\text { viaje en } \\
\text { motorhome, } \\
\text { camper, au- } \\
\text { tocaravana, } \\
\text { recreacional }\end{array}$ & $\begin{array}{l}\text { Turismo de } \\
\text { motorhomes }\end{array}$ & $\begin{array}{l}\text { - } \\
\text { viaje en au- } \\
\text { tocaravana } \\
\text { en Motor- } \\
\text { home }\end{array}$ & $\begin{array}{l}\text { - } \\
\text { Viajar en } \\
\text { camper, en } \\
\text { motorhomes } \\
\text { en casa ro- } \\
\text { dante, en au- } \\
\text { tocaravana }\end{array}$ \\
\hline 3 & cicloturismo & +1 & +1 & $\begin{array}{l}+2 \\
\text { Turismo en } \\
\text { dos ruedas } 2\end{array}$ & +2 & +2 \\
\hline 4 & $\begin{array}{l}\text { Enoturismo } \\
\text { T. enológico }\end{array}$ & $\begin{array}{l}+1 \\
+1\end{array}$ & $\begin{array}{l}+1 \\
+1\end{array}$ & $\begin{array}{l}+1 \\
+2\end{array}$ & $\begin{array}{l}+1 \\
+1\end{array}$ & $\begin{array}{l}+1 \\
+1\end{array}$ \\
\hline 5 & geoturismo & +2 & +2 & +2 & +2 & +2 \\
\hline 6 & $\begin{array}{l}\text { Miniturismo } \\
\text { Mini turismo }\end{array}$ & +1 & +2 & - & - & - \\
\hline 7 & oleoturismo & +1 & +2 & +2 (raro) & +2 & +2 \\
\hline
\end{tabular}

tal Colombia destino (https://www.colombiatudestino.com/), etc.

- México, el diario El Universal, el portal oficial visitMéxico (www.visitmexico.com), el portal altonivel (https://www.altonivel.com.mx/), etc.

- Perú: el diario El Comercio, el portal oficial (gobiernoperú turismo: https://www.mincetur.gob. pe/turismo/), el portal go2Peru (https://www.gozperu.com), https://adonde.com/, etc. 


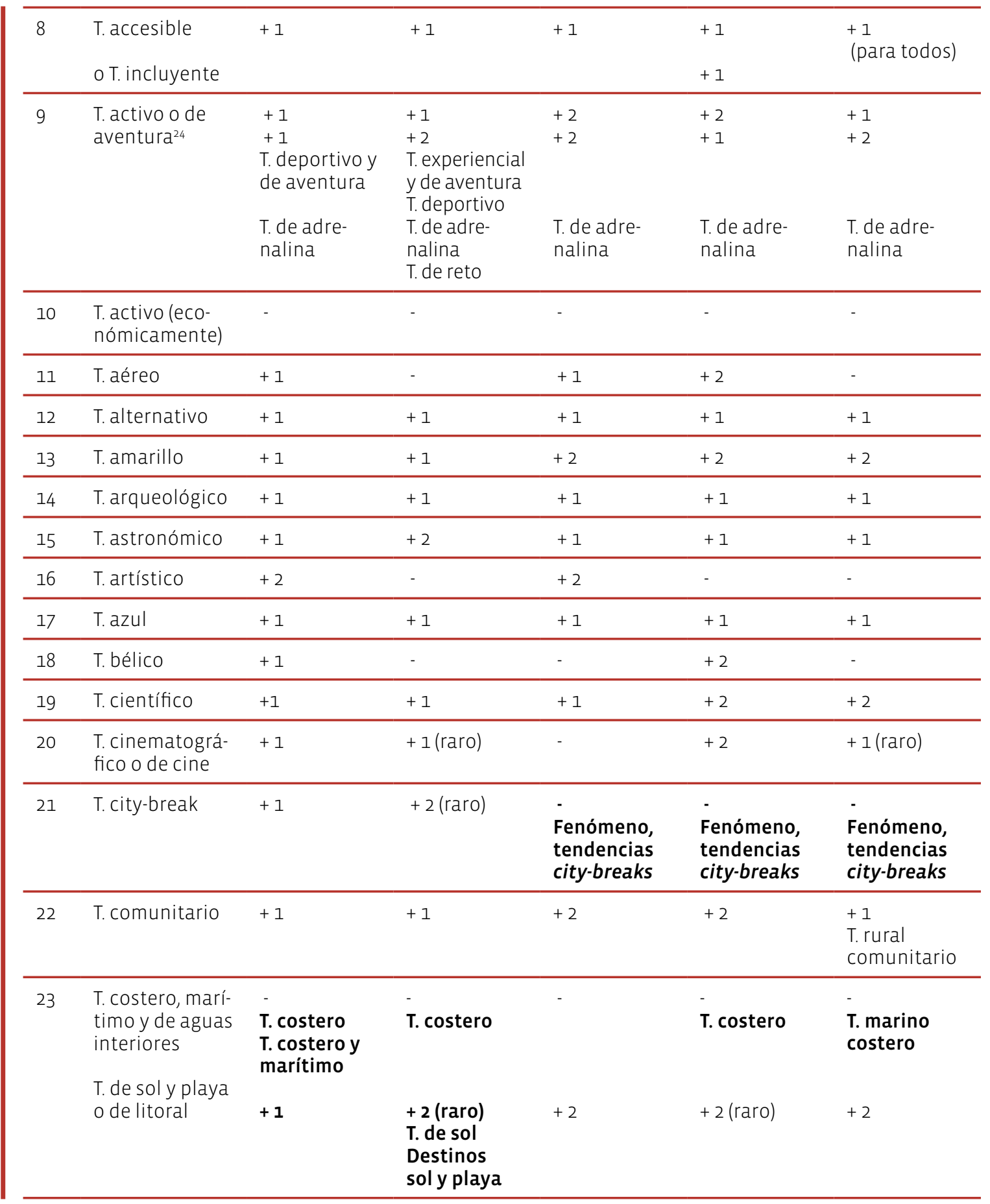

24 Las denominaciones pueden presentar múltiples variables. El libro blanco de la comunidad valenciana incluye T. activo y de naturaleza. 


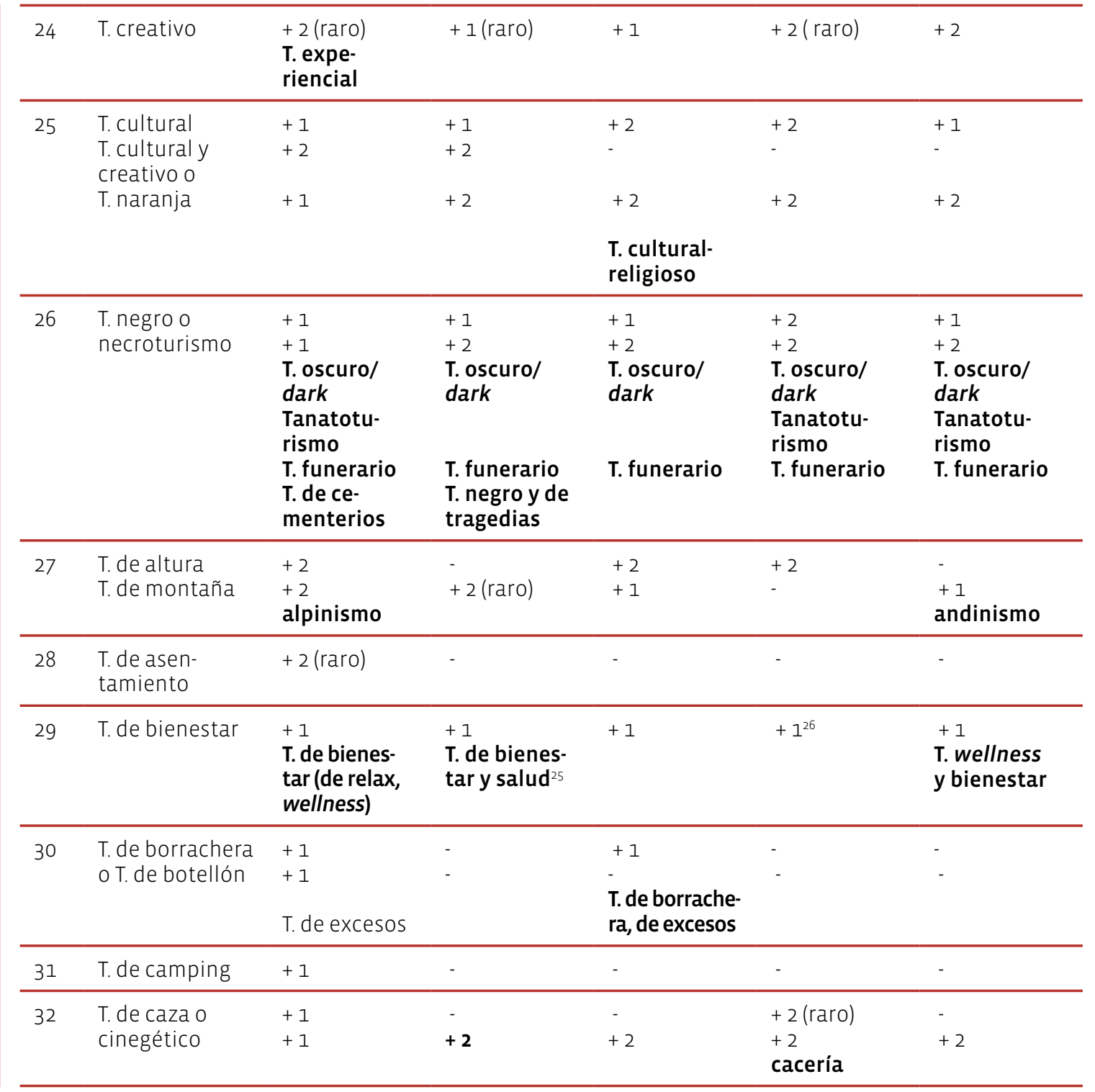

25 El turismo de bienestar se centra en la prevención para mantener o mejorar su salud o calidad de vida. Hemos observado que a veces se confunde el turismo de bienestar y el de salud, de hecho a veces se utilizan las dos denominaciones juntas.

26 En México, la Secretaría de Economía divide al turismo de salud en turismo médico (procedimientos quirúrgicos y tratamientos con medicamentos; procesos de orden ambulatorio, dentales, oftalmológicos y algunos cosméticos) y turismo de bienestar (realiza actividades orientadas al relajamiento, cambios de estilos de vida, spas, retiros espirituales, hogares de retiro y asistencia para personas de la tercera edad) (https://www.entornoturistico.com/el-turismo-de-salud-es-unode-los-sectores-mas-rentables-en-mexico-y-el-mundo/). 


\begin{tabular}{|c|c|c|c|c|c|c|}
\hline 33 & T. de compras & $\begin{array}{l}+1 \\
\text { T. de shop- } \\
\text { ping }\end{array}$ & $\begin{array}{l}+1 \\
\text { T. de shop- } \\
\text { ping }\end{array}$ & $\begin{array}{l}+2 \\
\text { T. de shop- } \\
\text { ping }\end{array}$ & $\begin{array}{l}+2 \\
\text { T. de shop- } \\
\text { ping }\end{array}$ & $\begin{array}{l}+2 \\
\text { T. de shop- } \\
\text { ping }\end{array}$ \\
\hline 34 & $\begin{array}{l}\text { T. de congresos } \\
\text { T. de ferias y } \\
\text { congresos } \\
\text { T. de reuniones, } \\
\text { congresos y } \\
\text { convenciones, } \\
\text { T. congresual } \\
\text { y ferial }\end{array}$ & $\begin{array}{l}+1 \\
+2\end{array}$ & $\begin{array}{l}- \\
- \\
+1 \text { T. de con- } \\
\text { venciones } \\
+1 \text { T. de reu- } \\
\text { niones y con- } \\
\text { venciones }\end{array}$ & $\begin{array}{l}+2 \\
-\end{array}$ & $\begin{array}{l}- \\
\text { T. de con- } \\
\text { venciones } \\
\text { T. de reunio- } \\
\text { nes y con- } \\
\text { venciones } \\
\text { T. de reunio- } \\
\text { nes, con- } \\
\text { venciones } \\
\text { y eventos }\end{array}$ & $\begin{array}{l}- \\
\text { T. de reu- } \\
\text { niones } \\
\text { T. de reunio- } \\
\text { nes y con- } \\
\text { venciones }\end{array}$ \\
\hline 35 & T. de cruceros & +1 & +1 & +1 & +1 & +1 \\
\hline 36 & T. de descanso & +1 & +2 & - & +2 (raro) & - \\
\hline 37 & T. de eventos & +1 & +1 & +1 & +1 & +1 \\
\hline 38 & T. de escapada & $\begin{array}{l}+1 \\
\text { T. de fin de } \\
\text { semana }\end{array}$ & $\begin{array}{l}\text { T. de fin de } \\
\text { semana }\end{array}$ & - & +2 & - \\
\hline 39 & $\begin{array}{l}\text { T. de excur- } \\
\text { siones }\end{array}$ & +2 (raro) & excursiones & excursiones & - & - \\
\hline 40 & $\begin{array}{l}\text { T. de expe- } \\
\text { riencia }\end{array}$ & $\begin{array}{l}+1 \\
\text { T. expe- } \\
\text { riencial }\end{array}$ & +2 & +2 & +2 & +2 (raro) \\
\hline 41 & T. de formación & +2 (raro) & - & - & - & - \\
\hline 42 & T. de golf & +1 & +2 & +2 & +1 & +2 (raro) \\
\hline 43 & T. de grupo & +1 & $\begin{array}{l}+1 \\
\text { T. de/en } \\
\text { grupo }\end{array}$ & $\begin{array}{l}+1 \\
\text { T. de/en } \\
\text { grupo }\end{array}$ & $\begin{array}{l}+1 \\
\text { T. de/en } \\
\text { grupo }\end{array}$ & $\begin{array}{l}+1 \\
\text { T. en grupo }\end{array}$ \\
\hline 44 & $\begin{array}{l}\text { T. de hechos } \\
\text { singulares }\end{array}$ & $\begin{array}{l}+2 \\
\text { T. de aconte- } \\
\text { cimientos } \\
\text { T. de acon- } \\
\text { tecimientos } \\
\text { singulares } \\
\text { T. de hechos } \\
\text { y eventos } \\
\text { singulares }\end{array}$ & - & - & - & - \\
\hline 45 & $\begin{array}{l}\text { T. de (la) } \\
\text { tercera edad }\end{array}$ & $\begin{array}{l}+1 \\
\text { T. de adultos } \\
\text { mayores }\end{array}$ & $\begin{array}{l}+1 \\
\text { T. de adultos } \\
\text { mayores }\end{array}$ & $\begin{array}{l}+1 \text { (raro) } \\
\text { T. de adultos } \\
\text { mayores }\end{array}$ & $\begin{array}{l}+2 \\
\text { T. de adultos } \\
\text { mayores }\end{array}$ & $\begin{array}{l}+2 \\
\text { T. de adultos } \\
\text { mayores }\end{array}$ \\
\hline \multirow[t]{2}{*}{46} & $\begin{array}{l}\text { T. de lujo y } \\
\text { reuniones }\end{array}$ & - & - & - & - & - \\
\hline & T. de lujo & +1 & +1 & +1 & +1 & +1 \\
\hline 47 & T. de masa & $\begin{array}{l}+2 \\
\text { T. masivo }\end{array}$ & $\begin{array}{l}+2 \\
\text { T. masivo }\end{array}$ & $\begin{array}{l}+2 \\
\text { T. masivo }\end{array}$ & $\begin{array}{l}+2 \\
\text { T. masivo }\end{array}$ & $\begin{array}{l}+2 \\
\text { T. masivo }\end{array}$ \\
\hline 48 & T. de naturaleza & +1 & +1 & +1 & +1 & +1 \\
\hline
\end{tabular}




\begin{tabular}{|c|c|c|c|c|c|c|}
\hline 49 & $\begin{array}{l}\text { T. de negocios } \\
\text { T. de comercio }\end{array}$ & $\begin{array}{l}+1 \\
-\end{array}$ & $\begin{array}{l}+1 \\
- \\
\text { T. de reu- } \\
\text { niones } \\
\text { T. de reunio- } \\
\text { nes y con- } \\
\text { venciones }\end{array}$ & $\begin{array}{l}+2 \\
- \\
\text { T. de reu- } \\
\text { niones }\end{array}$ & $\begin{array}{l}+2 \\
- \\
\text { T. de reu- } \\
\text { niones }\end{array}$ & $\begin{array}{l}+2 \\
- \\
\text { T. de reu- } \\
\text { niones }\end{array}$ \\
\hline 50 & T. de nicho & +2 & +2 & +2 (raro) & +2 & +2 \\
\hline 51 & $\begin{array}{l}\text { T. de nieve } \\
\text { T. de esquí y } \\
\text { montaña }\end{array}$ & $\begin{array}{l}+1 \\
\text { T. de esquí } \\
\text { T. de nieve } \\
\text { y montaña }\end{array}$ & +2 & - & - & $\begin{array}{l}- \\
\text { - } \\
\text { T. de aven- } \\
\text { tura esquí } \\
\text { nevado }\end{array}$ \\
\hline 52 & T. de ocio & +2 & +2 (raro) & +2 (raro) & +2 (raro) & $\begin{array}{l}+ \\
\text { T. de recrea- } \\
\text { ción y ocio }\end{array}$ \\
\hline 53 & $\begin{array}{l}\text { T. de parques } \\
\text { temáticos }\end{array}$ & +2 & - & - & - & - \\
\hline 54 & T. de paseo & +2 & +2 (raro) & - & +2 (raro) & - \\
\hline 55 & T. de paso & +2 & +2 & +2 & +2 & +2 \\
\hline 56 & T. de pesca & $\begin{array}{l}+1 \\
\text { T. pesquero }\end{array}$ & +2 & - & $\begin{array}{l}+2 \text { (raro) } \\
\text { T. pesquero }\end{array}$ & $\begin{array}{l}+2 \\
\text { T. pesquero }\end{array}$ \\
\hline 57 & T. de salud & +1 & +1 & +1 & +1 & +1 \\
\hline 58 & $\begin{array}{l}\text { T. de sol y playa } \\
\text { o de litoral }\end{array}$ & +1 & $\begin{array}{l}\text { + } 2 \text { (raro) } \\
\text { T. de sol } \\
\text { Destinos } \\
\text { sol y playa }\end{array}$ & +2 & $\begin{array}{l}+2 \text { (raro) } \\
\text { T. sol y playa }\end{array}$ & +2 \\
\hline 59 & $\begin{array}{l}\text { T. de vivienda } \\
\text { vacacional }\end{array}$ & $\begin{array}{l}\text { Vivienda de } \\
\text { uso turístico } \\
\text { Vivienda } \\
\text { vacacional }\end{array}$ & - & - & - & - \\
\hline 60 & T. de bisturí & $\begin{array}{l}+1 \\
\text { T. estético }\end{array}$ & T. estético & $\begin{array}{l}+2 \\
\text { T. estético }\end{array}$ & $\begin{array}{l}+2 \\
\text { T. estético }\end{array}$ & $\begin{array}{l}+2 \\
\text { T. estético }\end{array}$ \\
\hline 61 & T. deportivo & +1 & +1 & +2 & +1 & +1 \\
\hline 62 & $\begin{array}{l}\text { T. doméstico } \\
\text { o interior } \\
\text { o interno } \\
\text { o nacional }\end{array}$ & $\begin{array}{l}+1 \\
+1 \\
+1 \\
+1\end{array}$ & $\begin{array}{l}- \\
- \\
+1 \\
+2\end{array}$ & $\begin{array}{l}+2 \\
- \\
+2 \\
+2\end{array}$ & $\begin{array}{l}+2 \\
- \\
+2 \\
+2\end{array}$ & $\begin{array}{l}- \\
- \\
+2 \\
+2\end{array}$ \\
\hline 63 & $\begin{array}{l}\text { T. ecológico o } \\
\text { ecoturismo }\end{array}$ & $\begin{array}{l}+1 \\
+1 \\
\text { T. ambiental }\end{array}$ & $\begin{array}{l}+1 \\
+1\end{array}$ & $\begin{array}{l}+1 \\
+1 \\
\text { T. de na- } \\
\text { turaleza }\end{array}$ & $\begin{array}{l}+1 \\
+1\end{array}$ & $\begin{array}{l}+1 \\
+1 \\
\text { T. de na- } \\
\text { turaleza y } \\
\text { conservación }\end{array}$ \\
\hline 64 & T. ecuestre & +1 & +1 & +1 & +2 & +2 \\
\hline
\end{tabular}




\begin{tabular}{|c|c|c|c|c|c|c|}
\hline 65 & T. educativo & $\begin{array}{l}+2 \\
\text { T. escolar } \\
\text { T. estudiantil }\end{array}$ & $\begin{array}{l}+1 \\
\text { T. escolar } \\
\text { T. estudiantil } \\
\text { T. de for- } \\
\text { mación }\end{array}$ & $\begin{array}{l}+2 \\
\text { T. escolar o } \\
\text { de apren- } \\
\text { dizaje } \\
\text { T. estudiantil } \\
\text { T. estudiantil }\end{array}$ & $\begin{array}{l}+2 \\
\text { T. estudiantil }\end{array}$ & $\begin{array}{l}+2 \\
\text { T. educativo } \\
\text { juvenil } \\
\text { T. estudiantil }\end{array}$ \\
\hline \multirow[t]{2}{*}{66} & T. étnico o & +1 & +2 & +2 & +2 & +2 \\
\hline & etnoturismo & +1 & +1 & +2 & +2 & +2 \\
\hline \multirow[t]{2}{*}{67} & T. exterior & +1 & +2 & - & - & - \\
\hline & T. extranjero & $\begin{array}{l}+1 \\
\text { T. receptor }\end{array}$ & +1 & +2 & $\begin{array}{l}+2 \\
\text { T. receptivo } \\
\text { de entrada }\end{array}$ & $\begin{array}{l}+2 \\
\text { T. receptivo }\end{array}$ \\
\hline 68 & T. familiar & $\begin{array}{l}+1 \\
\text { T. en familia }\end{array}$ & +1 & +1 & +2 & +2 \\
\hline 69 & T. ferroviaario & +1 & +2 & +2 & +2 & +2 \\
\hline 70 & T. folclórico & $\begin{array}{l}+2 \\
\text { T. folklórico }\end{array}$ & $\begin{array}{l}\text { Festival } \\
\text { folclórico }\end{array}$ & $\begin{array}{l}\text { Festival } \\
\text { folclórico }\end{array}$ & $\begin{array}{l}\text { México } \\
\text { folclórico }\end{array}$ & +2 \\
\hline 71 & T. gastronómico & $\begin{array}{l}+1 \\
\text { T. culinario }\end{array}$ & $\begin{array}{l}+1 \\
\text { T. culinario }\end{array}$ & $\begin{array}{l}+1 \\
\text { Food and } \\
\text { travel }\end{array}$ & $\begin{array}{l}+1 \\
\text { T. culinario }\end{array}$ & $\begin{array}{l}+1 \\
\text { T. culinario }\end{array}$ \\
\hline 72 & T. golondrina & +2 & +1 & +1 & +1 & +2 \\
\hline 73 & T. Histórico & +1 & +1 & +2 & +2 (raro) & $\begin{array}{l}\text { T. receptor } \\
\text { histórico }\end{array}$ \\
\hline 74 & T. idiomático & +1 & +1 & +2 & +1 & +2 \\
\hline 75 & $\begin{array}{l}\text { T. individual } \\
\text { T. single(s) } \\
\text { T. para soltero }\end{array}$ & $\begin{array}{l}+1 \\
+1 \\
+1 \\
\text { T. para single } \\
\text { Viajar sola } \\
\text { o solo }\end{array}$ & $\begin{array}{l}+2 \text { (raro) } \\
+1 \\
+2 \\
\text { Viajar sola } \\
\text { o solo }\end{array}$ & $\begin{array}{l}+2 \text { (raro) } \\
+2 \text { (raro) } \\
+2 \\
\text { Viajar solo }\end{array}$ & $\begin{array}{l}+2 \text { (raro) } \\
+2 \text { (raro) } \\
+2 \\
\text { Viaje para } \\
\text { soltero }\end{array}$ & $\begin{array}{l}- \\
+2 \text { (raro) } \\
+2\end{array}$ \\
\hline 76 & T. industrial & +1 & +2 & +2 (raro) & +2 & $\begin{array}{l}\text { - } \\
\text { Centro } \\
\text { turístico } \\
\text { industrial }\end{array}$ \\
\hline 77 & T. itinerante & +1 & +1 & - & +2 & - \\
\hline 78 & T. juvenil27 & $\begin{array}{l}+1 \\
\text { T. joven }\end{array}$ & +1 & +1 & $\begin{array}{l}+2 \\
\text { T. joven }\end{array}$ & $\begin{array}{l}+2 \\
\text { T. para los } \\
\text { jóvenes }\end{array}$ \\
\hline 79 & T. literario & +1 & +1 & +2 & +1 & +2 \\
\hline 80 & T. LGBT & $\begin{array}{l}+1 \\
\text { T. gay } \\
\text { T. LGTBI } \\
\text { T. LGBTII }\end{array}$ & $\begin{array}{l}+1 \\
\text { T. gay } \\
\text { T. LGTBI }\end{array}$ & $\begin{array}{l}+1 \\
\text { T. gay }\end{array}$ & $\begin{array}{l}+1 \\
\text { T. gay } \\
\text { T. de parejas } \\
\text { del mismo } \\
\text { sexo }\end{array}$ & $\begin{array}{l}+2 \\
\text { T. gay }\end{array}$ \\
\hline
\end{tabular}




\begin{tabular}{|c|c|c|c|c|c|c|}
\hline 81 & T. lúdico-festivo & +2 & - & - & T. festivo & - \\
\hline 82 & T. médico & +1 & +1 & +1 & +1 & +1 \\
\hline \multirow[t]{2}{*}{83} & T. micológico o & +1 & +2 & - & +2 & - \\
\hline & micoturismo & +2 & +1 & +2 & +2 & +2 \\
\hline 84 & T. musical & +1 & +1 & +2 & +2 & +1 \\
\hline 85 & T. naranja & +1 & +1 & +2 & +2 & +1 \\
\hline 86 & T. ornitológico & +1 & +2 & +1 & +2 & +2 \\
\hline 87 & T. recreativo & +2 & +1 & +2 & +2 (raro) & +2 \\
\hline 88 & T. religioso & $\begin{array}{l}+1 \\
\text { T. espiritual }\end{array}$ & $\begin{array}{l}+1 \\
\text { T. espiritual }\end{array}$ & $\begin{array}{l}+2 \\
\text { T. espiritual }\end{array}$ & $\begin{array}{l}+1 \\
\text { T. espiritual }\end{array}$ & $\begin{array}{l}+1 \\
\text { T. místico y } \\
\text { espiritual }\end{array}$ \\
\hline 89 & T. residencial & +1 & +2 & +2 & +2 & +2 \\
\hline 90 & T. rural & +1 & $\begin{array}{l}+1 \\
\text { T. agrícola o } \\
\text { agroturismo }\end{array}$ & +2 & +2 & +1 \\
\hline 91 & T. responsable & +1 & +1 & +1 & +1 & +1 \\
\hline 92 & T. rojo & +1 & +1 & +1 & +1 & +1 \\
\hline 93 & T. sexual & $\begin{array}{l}+1 \\
\text { sexoturismo }\end{array}$ & $\begin{array}{l}+1 \\
\text { sexoturismo }\end{array}$ & $\begin{array}{l}+1 \\
\text { sexoturismo }\end{array}$ & $\begin{array}{l}+1 \\
\text { sexoturismo }\end{array}$ & $\begin{array}{l}+1 \\
\text { sexoturismot }\end{array}$ \\
\hline 94 & T. social & +1 & +1 & +1 & +1 & +1 \\
\hline 95 & T. sostenible & +1 & $\begin{array}{l}+1 \\
\text { T. susten- } \\
\text { table }\end{array}$ & $\begin{array}{l}+2 \\
\text { T. susten- } \\
\text { table }\end{array}$ & $\begin{array}{l}+1 \\
\text { T. susten- } \\
\text { table }\end{array}$ & +1 \\
\hline 96 & $\begin{array}{l}\text { T. solidario o } \\
\text { de volun- } \\
\text { tariado }\end{array}$ & $\begin{array}{l}+1 \\
+2\end{array}$ & $\begin{array}{l}+1 \\
+2\end{array}$ & +1 & $\begin{array}{l}+1 \\
+2\end{array}$ & +1 \\
\hline 97 & T. termal & $\begin{array}{l}+2 \\
\text { termalismo }\end{array}$ & $\begin{array}{l}+1 \\
\text { termalismo }\end{array}$ & +2 & +1 & $\begin{array}{l}+2 \\
\text { termalismo }\end{array}$ \\
\hline 98 & T. terrestre & +2 & +2 & - & +2 & - \\
\hline 99 & $\begin{array}{l}\text { T. urbano } \\
\text { T urbano o } \\
\text { de ciudad }\end{array}$ & $\begin{array}{l}+1 \\
+2\end{array}$ & +1 & $\begin{array}{l}+2 \\
-\end{array}$ & $\begin{array}{l}+2 \\
+2 \text { (raro) }\end{array}$ & $\begin{array}{l}+2 \\
-\end{array}$ \\
\hline
\end{tabular}

27 A partir de una tipología de turismo que aparece en una de las diferentes clasificaciones, por ejemplo, T. juvenil, la búsqueda de ocurrencias nos permite encontrar otras denominaciones referidas a esta tipología. Por ejemplo, para turismo juvenil, turismo joven o incluso turismo millenial, que conviene analizar detenidamente en cada caso para determinar si corresponden exactamente a la misma denominación. 


\begin{tabular}{|c|c|c|c|c|c|c|}
\hline 100 & T. vacacional & +2 & - & +2 & - & - \\
\hline 101 & T. verde & +2 & +1 & +1 & +2 & +1 \\
\hline & TOTAL 124 & $\begin{array}{l}+118 \\
-\quad 6 \\
1=96 \\
2=22\end{array}$ & $\begin{array}{l}+\quad 91 \\
-\quad 22 \\
1=61 \\
2=20\end{array}$ & $\begin{array}{r}+\quad 89 \\
-\quad 25 \\
1=28 \\
2=51\end{array}$ & $\begin{array}{r}+\quad 90 \\
-\quad 24 \\
1=24 \\
2=56\end{array}$ & $\begin{array}{r}+\quad 75 \\
-\quad 49 \\
1=28 \\
2=29\end{array}$ \\
\hline
\end{tabular}

\subsection{Análisis de los resultados}

\subsubsection{Tipos de turismo y su uso por país}

Si comparamos los resultados finales de los contenidos de los dos cuadros, se aprecia a simple vista que existe una gran diferencia entre el contenido de tipos de turismo que aparecen en las GOT analizadas y el número y tipos de turismo que existen en el sector del turismo. En efecto, frente a unos escasos contenidos de tipos de turismo en las GOT (ver tabla 4), observamos que, por contra, existen muchos más TT en el sector del turismo, como lo atestiguan los resultados y las ocurrencias que aparecen realmente en periódicos y en páginas webs de los cinco países analizados (ver tabla 5).

\section{TABLA 4}

Tipos de turismo presentes en las GOT

\begin{tabular}{lllllllll} 
TIPO TUR & ESP 2015 & ESP 2020 & ARGENT & COL & MÉX & PERÚ & CDTS & UTD \\
\hline TOTAL: 62 & $22=35 \%$ & $21=34 \%$ & $22=35 \%$ & $29=47 \%$ & $17=27 \%$ & $11=18 \%$ & $20=31 \%$ & $17=27 \%$ \\
\hline
\end{tabular}

\section{TABLA 5}

Tipos de turismo presentes en periódicos y págs. webs

$\begin{array}{lccccc}\begin{array}{l}\text { TT EN PERIÓDICOS } \\ \text { Y PÁGS. WEBS }\end{array} & \text { ESPAÑA } & \text { ARGENTINA } & \text { COLOMBIA } & \text { MÉXICO } & \text { PERÚ } \\ & & & & & \\ & & & & & \\ \text { TOTAL } \mathbf{1 2 4} & 118=90 \% & 92=74 \% & 89=72 \% & 90=73 \% & 75=60 \% \\ & -6 & -22 & -25 & -24 & -49 \\ & 1=96 & 1=61 & 1=28 & 1=24 & 1=28 \\ & 2=22 & 2=20 & 2=51 & 2=56 & 2=29 \\ & & & & & \\ \end{array}$

La metodología utilizada para acreditar la existencia y el uso de los TT ha consistido en buscar primero en la prensa y en caso de no aparecer a continuación en los servidores especializados 
en turismo ${ }^{28}$. La combinación de prensa referencial y páginas especializadas en turismo arroja unos resultados muy elocuentes que atestiguan no solamente la existencia de los TT, con sus posibles variantes, sino la importancia en las investigaciones textuales de elaborar corpus textuales a partir de medios y soportes variados y complementarios. Los resultados muestran:

- que dos periódicos, El País y Clarín, contienen un número de referencias a los TT que forman parte del cuadro 3 muy superior al de los diarios referenciales de Colombia, México y Perú;

- que la combinación de medios de consulta españoles es la que permite encontrar más TT (con un 90\%), seguida de Argentina, México y Colombia con un porcentaje que oscila entre el 72 y el $74 \%$. Finalmente, la combinación de medios peruanos es, por ahora, la que ha permitido encontrar menos TT con un 60\% de casos.

\subsubsection{Usos comunes de denominaciones de TT}

El análisis de los resultados que aparecen en el cuadro 3 permite extraer también usos de denominaciones de TT comunes:

- Denominaciones de tipologías de turismo que coinciden en los cinco países:

- TT que usan una sola y misma denominación en los 5 países: astroturismo, cicloturimo, geoturismo, micoturismo, oleoturismo, T. accesible, T. alternativo, T. amarillo, T. arqueológico, T. astronómico, T. azul, T. científico, T. comunitario, T. creativo, T. de bienestar, T. cinegético, T. de cruceros, T. de eventos, T. de experiencia, T. de golf, T. de grupo, T. de negocios, T. de ocio, T. de paso, T. de salud, T. de tercera edad, T. de sol y playa, T. deportivo, T. ecuestre, T. educativo, T. familiar, T. extranjero, T. interno, T. ferroviario, T. gastronómico, T. golondrina, T. idiomático, T. juvenil, T. literario, T. musical, T. nacional, T. naranja, T. ornitológico, T. religioso, T. rural, T. social, T. solidario, T. urbano, T. termal, T. verde.

50 TT, es decir, el 51\% de los tipos de turismo analizados en este trabajo, utilizan una sola y misma denominación en los cinco países.

- Tipologías de turismo que usan varias denominaciones, idénticas en cada caso en los cinco países. Se han encontrado en este caso varias posibilidades:

28 La gran cantidad de TT y de búsquedas a realizar nos ha llevado a no buscar los TT primero en las páginas especializadas de turismo. Esto podría ser claramente objeto de una investigación posterior de cara a observar cuál de los dos medios incluye más TT o si los periódicos, los servidores especializados en turismo y los trabajadores del turismo usan la misma terminología. Valga como muestra el siguiente ejemplo sacado de la fila 72 del cuadro 3 relacionado con el T. de solteros. En el periódico El Comercio de Perú y en las páginas webs analizadas aparecen ejemplos contextualizados que usan T. single y T. para soltero, pero por lo general en las agencias de viaje peruanas usan FIT o Foreign Individual Tourism. 
- Los cinco países utilizan dos denominaciones para el mismo TT. Ejs.: astroturismo / T. astronómico, T. de compras / T. de shopping, T. sexual / sexoturismo, enoturismo / T. enológico, T. ecológico / ecoturismo, T. étnico / etnoturismo, T. de masa / T. masivo, T. interno / T. nacional, T. religioso / T. espiritual.

- Los cinco países utilizan tres denominaciones para el mismo TT. Ejs.: T. cultural / T. cultural y creativo / T. naranja, T. activo / T. de aventura / T. de adrenalina, T. educativo / T. escolar / T. estudiantil.

- Los cinco países utilizan cuatro denominaciones para el mismo TT. Ejs.: T. negro / necroturismo / T. oscuro / T. funerario, T. single(s) / T. para soltero, T. LGBT / T. gay.

- Denominaciones de TT que no coinciden en los 5 países:

- TT que usan una misma denominación y que no coinciden en los cinco países. Ejs.:

- Tipologías de turismo que solamente se usan en uno de los países analizados. Así, por ejemplo, se utiliza la forma turismo city-break en España y en Argentina, mientras que Colombia, México y Perú emplean la denominación fenómeno, tendencias city-break. Es también el caso de caravaning, T. de camping, T. de asentamiento, T. de formación, T. de excursiones, T. de hechos singulares, T. de parques temáticos, T. lúdico-festivo.

- Tipologías de turismo que solamente se usan en dos de los países analizados. Es el caso de miniturismo, T. cultural, T. de borrachera, T. de nieve, T. folclórico, T. vacacional.

- Tipologías de turismo que solamente se usan en tres de los países analizados. Es el caso de T. aéreo, T. cinematográfico o T. de cine, T. de paseo, T. doméstico, T. itinerante, T. micológico.

- Tipologías de turismo que reciben más de una denominación que no coinciden en los 5 países. Ejs.: T. activo / T. de aventura, T. urbano / T. de ciudad, T. de comercio / T. de negocios, T. de nieve / T. de esquí / T. de esquí y montaña, T. accesible / T. incluyente, T. de borrachera / T. de botellón. Hemos comentado anteriormente la importancia de elaborar corpus textuales a partir de medios y soportes variados y complementarios.

- Tipologías de turismo que, aunque hayan aparecido en GOT o en artículos de investigación, sin embargo, no se han podido encontrar en las fuentes textuales consultadas. Se trata de T. activo, T. costero, marítimo y de aguas interiores (T. costero), T. de lujo y de reuniones (T. de lujo), T. de vivienda vacacional, T. de esquí y montaña.

\subsubsection{Casos no coincidentes}

En los casos restantes, es decir, en los casos de denominaciones de los TT que no coinciden en algunos de los cinco países, no se ha detectado ninguna tipología clara o dominante de formación de denominaciones nuevas o de variaciones, al contrario de lo que se ha observado 
en la formación de unidades fraseológicas en Hispanoamérica, por ejemplo, que permitan elaborar tipologías de formación, de variación, de uso diferencial. En efecto, las variaciones en las denominaciones no permiten configurar tipologías de uso ni saber por qué en España, Argentina, Colombia y México utilizan T. religioso y T. espiritual, mientras que en Perú se han encontrado ocurrencias para T. religioso y T. místico y espiritual. Con toda seguridad, el uso de los TT utilizados en cada país varía en función de las peticiones de los turistas y podría explicar por qué un tipo de turismo aparece en algunos países y no en otros. Es el caso, por ejemplo, de T. de borrachera o T. de botellón²9. Finalmente, otra posible causa puede estar ligada al uso variacional o preferencial de ciertos sustantivos o adjetivos. Sería el caso ya comentado de T. sostenible o sustentable, de T. receptor en España frente a T. receptivo en México y en Perú, o de T. alpino y alpinismo en España frente a T. andino y andinismo en Perú.

Finalmente, conviene destacar que de los 101 TT utilizados en el marco de esta investigación no se han encontrado ocurrencias ni referencias en 5 de los periódicos y páginas webs consultados que forman parte de la segunda parte de este estudio.

Los resultados y las conclusiones parciales que se están formulando se basan en la consulta de la información digitalizada presente en los dos medios señalados. La representatividad de esos dos medios podría ser objeto de estudios posteriores de cara a analizar si los periódicos y las páginas webs consultadas de los cinco países reproducen el lenguaje utilizado a diario por los habitantes de los cinco países o, por el contrario, se ha producido consciente o inconscientemente, por motivos lingüísticos o económicos, un uso transnacional nivelador, de cara a permitir a usuarios de diferentes países que utilicen el español como lengua oficial para comunicarse de manera más efectiva.

\section{Conclusión}

El mundo del turismo ha pasado de ser un fenómeno social y elitista a otro de masas. Simultáneamente, las posibilidades de contratación o de consulta de servicios turísticos se han visto modificadas permitiéndole al turista-viajero consultar la oferta turística a través de la inmensa red informativa presente en internet.

29 Se trata de un tipo de fiesta muy extendido en España y practicado por los jóvenes estudiantes españoles ciertos días de la semana, de preferencia el jueves (pues muchos estudiantes vuelven a sus domicilios familiares el viernes), o los fines de semana. En ambos casos está ligado al deseo de socializar y de no pagar precios muy altos por las consumiciones. A su vez, jóvenes turistas británicos, franceses e incluso alemanes contratan esa modalidad (que ha tomado la denominación de las reuniones de los jóvenes españoles) para venir a pasar unas horas o una semana de "vacaciones en España”. Véase, por ejemplo, el siguiente enlace: https://www.diariodelviajero.com/europa/ el-turismo-del-botellon. 
Los resultados de la primera parte de este estudio muestran de manera clara que sorprendentemente el contenido en TT de las guías oficiales de España, Argentina, Colombia, México y Perú, así como en los documentos de la OMT, es muy reducido. No se comprende este contenido tan limitado, máxime por cuanto se trata de guías oficiales de países u organismos oficiales relevantes en el sector del turismo que se supone deberían hacer una presentación del mismo con un fuerte contenido descriptivo y tipológico de los productos y tipos de turismos que existen en cada país. Se trata de mostrar y evidenciar la diversidad y la calidad para crear una diferencia competitiva con otros países.

Este análisis, si bien ha recopilado unas cien denominaciones de turismos, dista mucho de ser y estar completo. Existen otros muchos tipos o denominaciones que estudios más exhaustivos podrían tratar. Es el caso, por ejemplo, de T. virtual, T. penitenciario, T. biocultural, T. de guerra, T. de marihuana, T. de juegos, T. atómico, T. de pueblos abandonados, T. mochilero, etc., ejemplos recopilados durante la investigación de este trabajo, en los periódicos señalados.

En la segunda parte, en la que se deseaba analizar el uso y las denominaciones de los tipos de turismo desde una óptica diatópica, de cara a saber si se utilizaba en los cinco países la misma terminología, los resultados evidencian una clara tendencia a utilizar por lo general las mismas denominaciones para los tipos de turismo analizados. En efecto, las denominaciones de TT que coinciden en los cinco países usando una única pero idéntica denominación sumadas a las que usan también simultáneamente dos, tres y cuatro denominaciones para un mismo TT en los países analizados suponen:

- 64 TT de los 101 que figuran en el cuadro 3 (es decir 63\%)

- y 84 de las 124 denominaciones (es decir 67\%) que figuran en el mismo cuadro.

Por otro lado, solamente en 5 de los 98 TT que forman parte de la segunda parte de este estudio no se han encontrado ocurrencias ni referencias en los periódicos y en las páginas webs consultadas. Estos resultados, que se apoyan en la lingüística de corpus, provienen de la combinación complementaria de medios señalados. Queda cada vez más patente que la lingüística de corpus, y en este caso la digitalización o el formato electrónico de los recursos lingüísticos presentes en la enorme red de recursos presentes en la web, posibilita extraer información de manera fiable y recurrente no solamente para búsquedas en lenguas normativas o generales, sino también en las lenguas de especialidad.

\section{Bibliografía citada}

Alcaraz, Enrique, Brian Hugues, Miguel-Ángel Campos-Pardillos, Víctor Pina y Marian Alesón, 2006 [2000]: Diccionario de términos de turismo y de ocio. Inglés-español, Spanish-English, Barcelona: Ariel. 
Beltrán, Miguel-Ángel, y María-Concepción Parra-Meroño, 2017: "Perfiles turísticos en función de las motivaciones para viajar”, Cuadernos de Turismo 39, 41-65.

CaLvı, Maria Vittoria, 2000: Il linguaggio spagnolo del turismo, Viareggio: M. Baroni.

Calvi, Maria Vittoria, y Giovanna Mapellı, 2011: La lengua del turismo: Géneros discursivos y terminología, Berna: Peter Lang.

Felipe De Souza, Ángela María, 2008: “El léxico en el discurso turístico en la enseñanza de E/LE: ¿Qué léxico enseñar y cómo enseñar?” en Dolores Azorín, María Belén Alvarado, Jaume Climent de Benito, M. Isabel Guardiola, Ruth Lavale-Ortiz, Carmen Marimón, José Joaquín Martínez, Xose A. Padilla, Herminia Provencio, Isabel Santamaría-Pérez, Larissa Timofeeva y Elena Toro (eds.): El diccionario como puente entre las lenguas y culturas del mundo: actas del II Congreso Internacional de Lexicografía Hispánica, Alicante: Biblioteca Virtual Miguel de Cervantes, 458-466.

González, Diana, y Miguel-Ángel Candel, 2018: "La neología del turismo 2.0”, Trans. Revista de Traductología 22, 81-97.

Molina, Arturo, David Martín-Consuegra, Agueda Esteban y Estrella Díaz, 2007: "Segmentación de la demanda turística: un análisis aplicado a un destino de turismo cultural", Revista de Análisis Turístico 4, 36-48.

Sanmartín, Julia, 2012: "Aplicaciones lexicográficas de un corpus de discurso turístico. Contextos de uso y definiciones", Pasos: Revista de Turismo y Patrimonio Cultural, 127.142.

Sanmartín, Julia, 2016: "Variación léxica geolectal, legislación sectorial y estandarización: las denominaciones de los establecimientos de alojamiento turísticos en el español de América”, ELUA 20, 257-274.

Suau-Jiménez, Francisca, 2015: "Traducción de calidad de webs hoteleras: discurso interpersonal e implicación del cliente”, Onomázein 22, 152-170.

URRetA OKeranza, Eguzkiñe, 2019: Diseño de productos y servicios turísticos locales, Madrid: Paraninfo.

\subsection{Guías planes de turismo consultadas}

\section{Argentina}

Plan Federal Estratégico de Turismo Sustentable 2025.

https://www.mininterior.gov.ar/planificacion/pdf/Plan-Federal-Estrategico-Turismo-Sustentable-2025.pdf. 


\section{España}

Plan Nacional e Integral de Turismo (2015).

https://turismo.gob.es/es-es/servicios/Documents/Plan-Nacional-Integral-Turismo-2012-2015.pdf.

Plan del Turismo Español Horizonte 2020.

https://www.tourspain.es/es-es/Conozcanos/Documents/HistoricoPoliticaTuristica/PlanTurismoEspanolHorizonte2020.pdf.

Libro blanco para una nueva estrategia turística de la Comunitat Valenciana. Generalitat Valenciana. http://www.turisme.gva.es/turisme/es/files/pdf/Libro_Blanco_Turismo_Comunitat_Valenciana.pdf.

\section{Colombia}

Plan Sectorial de Turismo (2018-22).

https://www.mincit.gov.co/CMSPages/GetFile.aspx?guid=2ca4ebd7-1acd-44f-99984c826bab5012.

\section{México}

Programa Sectorial de Turismo (2012-18).

http://www.sectur.gob.mx/wp-content/uploads/2014/01/programa_turismo.pdf.

\section{Perú}

Plan Estratégico Nacional de Turismo (2012-21).

https://www.academia.edu/7786041/Plan_Estrat\%C2\%Aggico_Nacional_de_Turismo_2012-2021_ PENTUR_?email_work_card=title.

\section{Organización Mundial de Turismo, OMT}

OMT/UNWTO. UNWTO TOurism definitions.

https://www.e-unwto.org/doi/pdf/10.18111/9789284420858.

OMT, Collection Of Domestic Tourism Statistics, 2004: A Technical Manual 3, Madrid, versión española. 